\title{
THE GLASS TRANSITION TEMPERATURE AND TEMPERATURE DEPENDENCE OF ACTIVATION ENERGY OF VISCOUS FLOW OF OVALBUMIN
}

\author{
KAROL MONKOS \\ Department of Biophysics, School of Medicine with the Division of Dentistry in Zabrze, Medical University of Silesia, H. Jordana 19, \\ 41-808 Zabrze 8, Poland
}

Received September 07, 2016; accepted October 17, 2016; published online October 24, 2016

\begin{abstract}
The paper presents the results of viscosity determinations on aqueous solutions of ovalbumin at a wide range of concentrations and at temperatures ranging from $5^{\circ} \mathrm{C}$ to $55^{\circ} \mathrm{C}$. On the basis of these measurements and three models of viscosity for glass-forming liquids: Avramov's model, free-volume model and power-law model, the activation energy of viscous flow for solutions and ovalbumin molecules, at different temperatures, was calculated. The obtained results show that activation energy monotonically decreases with increasing temperature both for solutions and ovalbumin molecules. The influence of the energy of translational heat motion, protein-protein and protein-solvent interactions, flexibility and hydrodynamic radius of ovalbumin on the rate of decrease in activation energy with temperature has been discussed. One of the parameters in the Avramov's equation is the glass transition temperature $T_{\mathrm{g}}$. It turns out that the $\mathbf{T}_{\mathrm{g}}$ of ovalbumin solutions increases with increasing concentration. To obtain the glass transition temperature of the dry ovalbumin, a modified Gordon-Taylor equation is used. Thus determined the glass transition temperature for dry ovalbumin is equal to $(231.8 \pm 6.1) \mathrm{K}$.
\end{abstract}

\section{INTRODUCTION}

The major proteins in egg white are: lysozyme, ovomucin, ovotransferrin and ovalbumin (Abeyrathne et al., 2014). These proteins - after separation - are used in food processing and as pharmaceuticals or antimicrobial agents. Ovalbumin is a phosphoglycoprotein and constitutes about $54 \%$ of total egg white proteins. This protein is a monomer with molecular mass of $\mathrm{M}_{\mathrm{p}}=45$ $\mathrm{kDa}$ and its complete amino acid sequence is well known (Nisbet et al., 1981). Ovalbumin consists of a single polypeptide chain of 385 amino acid residues that fold into a globular conformation with nine $\alpha$-helices, three $\beta$-sheets and three short helical segments of three to four residues (Stein et al., 1991; McCarty \& Worrall, 1997). During electrophoresis of ovalbumin form three distinguishable fractions with two, one and zero phosphate groups per molecule. However, the overall conformation of ovalbumin in each fraction is the same (Ahmad \& Salahuddin, 1976). Study of ovalbumin by $\mathrm{X}$-ray crystallography showed that the ovalbumin molecule is approximately a tri-axial ellipsoid with overall dimensions $7 \times 4.5 \times 5 \mathrm{~nm}$ (Stein et al., 1991). Ovalbumin has been the subject of many physicochemical studies by using different experimental techniques (Kang et al., 2014; Yang et al., 2013; Lin et al., 2012; Khodarahmi et al., 2009; Monkos, 2007; Tani et al., 2004; Renault et al., 2002; Ikeda \& Nishinari, 2001; Monkos, 2000 and references therein). As a result many of its physicochemical properties is well known and ovalbumin is widely used as a standard protein in various biophysical studies. However, it should be emphasized that up to now the function of ovalbumin is still unknown. Therefore, further study of its properties from different points of view is highly desirable.

This paper presents an analysis of the results of viscosity measurements for ovalbumin aqueous solutions at temperatures ranging from $5^{\circ} \mathrm{C}$ to $55^{\circ} \mathrm{C}$ and at a wide range of concentrations. The viscositytemperature dependence, for a fixed concentration of ovalbumin, is analyzed based on the three parameter equations resulting from the Avramov's model (Avramov, 1998), free volume model (Vinogradov \& Malkin, 1980) and power-law model (Taborek et al., 1986). One of the main purposes of the work is the determination of the glass transition temperature for the solutions of ovalbumin and dry ovalbumin. This temperature has been determined from the Avramov's model for each measured concentration of ovalbumin. On the other hand, to determine the glass transition temperature of dry ovalbumin, a modified GordonTaylor formulae has been applied. The other important parameter specified in the work is activation energy of 
viscous flow. Using the standard definition of the activation energy of viscous flow and the equations resulting from the above mentioned models, the analytical equations for the activation energy of the solution has been established. Then, for each model the mean values of viscous flow activation energy of ovalbumin, over the whole range of measured temperatures, has been determined.

\section{MATERIALS}

The crystalline chicken ovalbumin (grade V) was purchased from Sigma and into the measurements was used without further purification. From the crystalline form ovalbumin was directly dissolved in chilled distilled water. The solution thus obtained was passed through a paper filter to remove any dust particles or undissolved fragments. The solutions prepared for the measurements were stored in a refrigerator at $4^{\circ} \mathrm{C}$ until just prior to viscometry measurements, when they were wormed from $5^{\circ} \mathrm{C}$ to $55^{\circ} \mathrm{C}$. The $\mathrm{pH}$ values of such obtained solutions slightly changed in the range of measured concentrations with the average value 6.4. This means that the solutions were outside of the isoelectric point for ovalbumin which is in the range (4.59-4.71) (Young, 1963).

\section{VISCOMETRY}

Viscosity measurements of ovalbumin solutions carried out by Lefebvre showed that these solutions behave as Newtonian fluids (Lefebvre, 1982). The results of this study are important because they justify the use of viscometry for viscosity measurements of ovalbumin solutions. In the present study, the viscosity measurements were performed by means of an Ubbelohde-type capillary microviscometer with a flow time for water of $28.5 \mathrm{~s}$ at $25^{\circ} \mathrm{C}$. All measurements were made using the same microviscometer placed in a water bath controlled thermostatically at an accuracy of $0.1{ }^{\circ} \mathrm{C}$. After reaching the required temperature for the thermostat, measurements were started after a few minutes of delay in order to the system may reach a state of equilibrium. During the measurements, the microviscometer was always in the same position. Flow times were recorded to within $0.1 \mathrm{~s}$. The viscosity measurements were made from $5^{\circ} \mathrm{C}$ to $55^{\circ} \mathrm{C}$, and for most concentrations by steps of $5^{\circ} \mathrm{C}$. At temperatures slightly higher than $55^{\circ} \mathrm{C}$ flow times of the ovalbumin solutions increase with increasing temperature and this indicates that thermal denaturation of ovalbumin begins. The viscosity of the ovalbumin solutions was measured for concentrations from $6.16 \mathrm{~kg} / \mathrm{m}^{3}$ up to $430 \mathrm{~kg} / \mathrm{m}^{3}$. The density of the solutions was determined by gravimetric method. Ovalbumin concentrations were determined using a dry weight method in which the solutions were dried at high temperature for several hours.

The proteins, and in particular ovalbumin, are present in solution in native form only in a specific $\mathrm{pH}$ range and within a relatively narrow temperature range. The lower limit of temperature is the freezing point of the solution and the upper limit is the temperature of protein denaturation. In this temperature range, the viscosity of protein solutions - especially for high concentrations changes significantly. Analytical dependence of solution viscosity on temperature can be obtained based on a number of models of a viscous liquid flow. Each of these models describes the mechanism of liquid flow in a different way and allows obtaining different types of information about the system under study. To the most important models may include Avramov's model (Avramov, 1998), free volume model which leads to the Vogel-Tammann-Fulcher's equation (Vinogradov \& Malkin, 1980), power-law model (Taborek et al., 1986) and model based on the application of the absolute rate theory to the process of flow that leads to the modified Arrhenius equation (Monkos, 1996). The last model was discussed in an earlier work (Monkos, 2007a). In this study, the results of viscosity measurements of avalbumin solutions were analyzed on the basis of the other models.

\section{THE GLASS-TRANSITION TEMPERATURE}

The biological activities of hydrated proteins are closely related with their three-dimensional conformation and slow fluctuating motion. The hydrated water behaves as a plasticizer and enhances the protein flexibility. Thanks to that fully hydrated protein at physiological conditions may take a large number of slightly different conformational substates and different conformations can be explored over time. Changes in the conformation of the protein are, in turn, associated with a slight modification of its energy. Like in glasses this can be described by the conformational energy landscape (Frauenfelder et al., 1991). According to this approach, a protein may be present in several different isoenergetic conformational substates, corresponding to the valleys in the protein energy landscape. The biological activities of protein like for instance ligand binding lead to at least small rearrangements of protein atoms and, in consequence, to transitions between its conformational substates. As lowering the temperature, conformational transitions between substates are increasingly slower and at a certain temperature protein is frozen in a specific substate. This temperature is called the glass transition temperature of the protein $\mathrm{T}_{\mathrm{g}, \mathrm{p}}$. At this temperature the properties of the protein that require flexibility, such as ligand binding, are not observed on a 
practical time scale (Noel et al., 1995). At temperatures above the glass transition temperature in the movements of the groups of atoms in a protein predominate anharmonic motions, as in the liquid state. In contrast, at temperatures below the $\mathrm{T}_{\mathrm{g}}$ the harmonic motions predominate, as in the solid state (Kuwai et al., 2006). Changes in properties of material from liquid-like to solid-like at Tg cause a drastic change in such physical quantities as heat capacity, elastic modulus, electrical resistance (Kakivaya \& Hoeve, 1975), free molecular volume, thermal expansion coefficient, dielectric coefficient (Bhandari \& Howes, 1999), viscosity (Doster, 2010) and mean-square atomic displacement in proteins (Frontzek et al., 2014). Sharp changes in these properties as a function of temperature are the basis for the direct determination of glass transition temperature. Depending on the characteristic of the test uses various experimental techniques, such as differential scanning calorimetry, differential thermal analysis, thermal mechanical analysis, Mössbauer spectroscopy, neutron scattering and others (Kuwai et al., 2006; Frontzek et al., 2014 and references therein).

Recently an indirect method of determining the glass transition temperature has been proposed (Monkos, 2014, 2015). It is based on viscosity measurements and Avramov's model (Avramov, 1998). In the present work, this method was used to determine the $T_{g}$ of the ovalbumin. Details of the Avramov's model are given below. One of the main result of this model is the dependence of viscosity $\eta$ of the liquid on temperature T. For solutions, when viscosity depends both on temperature and concentration, this dependence can be written in the following way:

$$
\eta(c, T)=\eta_{\infty}(c) \exp \left[\frac{\Theta(c)}{T}\right]^{\alpha(c)}
$$

where $\eta_{\infty}(c), \Theta(c)$ and $\alpha(c)$ are concentration dependent parameters. To adjust the viscosity obtained from the above equation to the experimental values of viscosity, the numerical values of the parameters $\eta_{\infty}(c), \Theta(c)$ and $\alpha(c)$ are required. The calculation of these parameters was performed using non-linear regression procedure in the computational statistical program. The numerical values thus obtained the parameters $\Theta(c)$ and $\alpha(\mathrm{c})$, which are the most important for the purposes of this study, for all measured concentrations of ovalbumin are summarized in Table 1. Figure 1 shows the results of viscosity measurements of ovalbumin solutions for the three concentrations, and the curve for the concentration of $\mathrm{c}=430 \mathrm{~kg} / \mathrm{m}^{3}$ shows a fit to the experimental points obtained from equation (1) with the parameters designated by the above method. As can be seen the function of formula (1) yields an excellent fit to the experimental points in the whole range of measured temperatures. An equally good fit is obtained for the other concentrations of ovalbumin.

The parameter $\Theta(c)$ in Avramov's equation is the complex quantity. It can be written in the form $\Theta(c)=$ $\mathrm{T}_{\mathrm{g}}(\mathrm{c}) \varepsilon^{1 / \alpha(\mathrm{c})}$, where $\mathrm{T}_{\mathrm{g}}(\mathrm{c})$ means the glass transition temperature for a solution and the quantity $\varepsilon$ is the ratio of the activation energy corresponding to its value at the maximum of the probability distribution function to a dispersity of the activation energy in glass transition temperature (Avramov, 1998). To determine $\mathrm{T}_{\mathrm{g}}(\mathrm{c})$, in addition to the value of $\Theta(c)$ and $\alpha(c)$, the numerical value of $\varepsilon$ is necessary. It can be determined using a modified Gordon-Taylor equation (Monkos, 2014, 2015).

According to the classical thermodynamic approach of Gordon and Taylor, glass transition temperature of the mixture depends on the $\mathrm{Tg}$ of components, and the strength of the interaction between them (Gordon \& Taylor, 1952). For aqueous solutions of proteins Gordon-Taylor equation is convenient to present in the following form (Monkos, 2014, 2015):

$$
T_{g}(c)=\frac{c\left(T_{g, p}-k \rho_{w} \xi T_{g . w}\right)+k \rho_{w} T_{g . w}}{c\left(1-k \rho_{w} \xi\right)+k \rho_{w}}
$$

where $\mathrm{T}_{\text {g.p }}$ and $\mathrm{T}_{\mathrm{g} . \mathrm{w}}$ are glass-transition temperature of the dry protein and water, respectively; the parameter $\mathrm{k}$ is related to the strength of protein-water interaction, $\rho_{\mathrm{w}}$ and $\xi$ are the water density and the effective specific volume of a protein, respectively; and $\mathrm{c}$ means the solution concentration in $\mathrm{kg} / \mathrm{m}^{3}$. The effective specific volume is a coefficient of proportionality between the effective molar volume and the molar mass of a macrosolute (Zimmerman \& Minton, 1993). For ovalbumin this quantity has been determined previously: $\xi=1.951 \times 10^{-3} \mathrm{~m}^{3} / \mathrm{kg}$ (Monkos, 2000). The glasstransition temperature of the bulk water has been experimentally established by a number of authors and the obtained values are insignificantly different from each other. It seems that the most commonly cited value is $\mathrm{T}_{\mathrm{g} . \mathrm{w}}=136 \mathrm{~K}$ (Johari et al., 1987; Hallbruker et al., 1989; Sartor et al., 1994; Teeter et al., 2001; Katkov \& Levine, 2004), and that value will use in this work. The function of equation (2) has therefore only two unknown parameters $\mathrm{T}_{\text {g.p }}$ and $\mathrm{k}$.

Experimental values of $\mathrm{T}_{\mathrm{g}}(\mathrm{c})$ should be determined from the relation $\Theta(\mathrm{c})=\mathrm{T}_{\mathrm{g}}(\mathrm{c}) \varepsilon^{1 / \alpha(\mathrm{c})}$ by appropriate selection of the value of $\varepsilon$. The value of this we determine by trial and error method so that the function of equation (2) fitted to the thus obtained $\mathrm{T}_{\mathrm{g}}(\mathrm{c})$ values give - in the limit of zero concentration - value of the 
glass transition temperature of the water. Using this method for ovalbumin, the value of $\varepsilon=23.9$ was obtained. Taking the numerical values of the parameters $\Theta(c)$ and $\alpha(c)$ from the Table 1 may now be calculated $\mathrm{T}_{\mathrm{g}}(\mathrm{c})$ of all measured concentrations of ovalbumin. The results are shown in the Figure (2). The function of the modified Gordon-Taylor relation (2) can be fitted to the experimental points and $\mathrm{T}_{\text {g.p }}$ and $\mathrm{k}$ have to be taken into account as adjustable parameters. Such calculations were made using non-linear regression procedure in the computational statistical program. This yielded a glass transition temperature of dry ovalbumin $\mathrm{T}_{\mathrm{g}, \mathrm{p}}=(231.8 \pm$ 6.1) $\mathrm{K}$ and the value of the parameter $\mathrm{k}=(2.165 \pm$ 0.266). As shown in the Figure (2), the curve obtained from the relation (2) gives a good fit to the $T_{g}(c)$ values obtained using the method described above.

Table 1. Numerical values of the parameters $\Theta(c)$ and $\alpha(c)$ from Avramov's model; $T_{o, s}(c)$ and $F_{s}(c)$ from the free-volume model and $\mathrm{T}_{\mathrm{p}}(\mathrm{c})$ and $\mu(\mathrm{c})$ from power-law model for all measured concentrations. They allow calculation of the activation energy of ovalbumin solutions from relations (5), (7) and (9) respectively. Values of the parameters are expressed as mean \pm SE.

\begin{tabular}{|c|c|c|c|c|c|c|}
\hline $\mathrm{c}\left[\mathrm{kg} / \mathrm{m}^{3}\right]$ & $\Theta(\mathrm{c})[\mathrm{K}]$ & $\alpha(c)$ & $\mathrm{T}_{0, \mathrm{~s}}(\mathrm{c})[\mathrm{K}]$ & $F_{s}(c)$ & $\mathrm{T}_{\mathrm{p}}(\mathrm{c})[\mathrm{K}]$ & $\mu(\mathrm{c})$ \\
\hline 6.16 & $385.3 \pm 15$ & $3.088 \pm 0.22$ & $145.4 \pm 7.3$ & $3.665 \pm 0.57$ & $224.5 \pm 3.1$ & $1.668 \pm 0.09$ \\
\hline 15.4 & $398.9 \pm 10$ & $2.940 \pm 0.13$ & $144.4 \pm 4.2$ & $3.788 \pm 0.34$ & $222.4 \pm 2.4$ & $1.741 \pm 0.07$ \\
\hline 19.0 & $402.4 \pm 21$ & $2.885 \pm 0.25$ & $143.1 \pm 7.8$ & $3.851 \pm 0.64$ & $222.3 \pm 4.0$ & $1.726 \pm 0.11$ \\
\hline 21.8 & $393.2 \pm 12$ & $3.014 \pm 0.16$ & $147.5 \pm 4.9$ & $3.571 \pm 0.38$ & $223.0 \pm 2.8$ & $1.734 \pm 0.08$ \\
\hline 36.0 & $383.9 \pm 7.9$ & $3.146 \pm 0.12$ & $152.6 \pm 3.3$ & $3.231 \pm 0.23$ & $225.9 \pm 1.7$ & $1.670 \pm 0.05$ \\
\hline 53.9 & $386.4 \pm 6.9$ & $3.124 \pm 0.10$ & $154.0 \pm 2.9$ & $3.164 \pm 0.20$ & $225.3 \pm 1.8$ & $1.701 \pm 0.05$ \\
\hline 66.3 & $390.1 \pm 12$ & $3.073 \pm 0.17$ & $151.1 \pm 5.1$ & $3.356 \pm 0.37$ & $225.5 \pm 3.0$ & $1.692 \pm 0.09$ \\
\hline 72.4 & $391.9 \pm 5.9$ & $3.049 \pm 0.08$ & $150.0 \pm 2.4$ & $3.434 \pm 0.18$ & $224.5 \pm 1.9$ & $1.715 \pm 0.05$ \\
\hline 73.4 & $387.9 \pm 7.2$ & $3.098 \pm 0.10$ & $152.2 \pm 2.7$ & $3.279 \pm 0.19$ & $224.8 \pm 2.1$ & $1.706 \pm 0.06$ \\
\hline 76.5 & $383.5 \pm 8.4$ & $3.157 \pm 0.13$ & $155.3 \pm 3.8$ & $3.067 \pm 0.19$ & $225.6 \pm 2.4$ & $1.684 \pm 0.07$ \\
\hline 115 & $387.5 \pm 4.7$ & $3.132 \pm 0.07$ & $153.0 \pm 2.2$ & $3.278 \pm 0.16$ & $227.0 \pm 1.4$ & $1.678 \pm 0.04$ \\
\hline 140 & $376.7 \pm 6.9$ & $3.310 \pm 0.12$ & $158.7 \pm 2.6$ & $2.940 \pm 0.17$ & $228.5 \pm 1.1$ & $1.659 \pm 0.03$ \\
\hline 144 & $381.6 \pm 3.7$ & $3.239 \pm 0.06$ & $157.4 \pm 1.4$ & $3.033 \pm 0.09$ & $226.9 \pm 1.1$ & $1.706 \pm 0.03$ \\
\hline 157 & $381.9 \pm 4.0$ & $3.255 \pm 0.06$ & $157.7 \pm 1.4$ & $3.049 \pm 0.09$ & $227.0 \pm 1.0$ & $1.722 \pm 0.03$ \\
\hline 169 & $378.7 \pm 5.8$ & $3.317 \pm 0.10$ & $158.9 \pm 2.2$ & $2.993 \pm 0.15$ & $227.8 \pm 1.2$ & $1.713 \pm 0.04$ \\
\hline 180 & $374.0 \pm 5.2$ & $3.417 \pm 0.10$ & $159.0 \pm 2.9$ & $3.019 \pm 0.19$ & $228.7 \pm 1.8$ & $1.709 \pm 0.06$ \\
\hline 194 & $369.1 \pm 5.4$ & $3.526 \pm 0.10$ & $159.1 \pm 2.1$ & $3.048 \pm 0.14$ & $228.5 \pm 1.5$ & $1.732 \pm 0.05$ \\
\hline 207 & $370.5 \pm 4.9$ & $3.526 \pm 0.10$ & $163.7 \pm 2.7$ & $2.798 \pm 0.17$ & $230.5 \pm 1.8$ & $1.701 \pm 0.06$ \\
\hline 213 & $372.9 \pm 5.2$ & $3.496 \pm 0.10$ & $162.6 \pm 2.7$ & $2.888 \pm 0.18$ & $230.5 \pm 1.7$ & $1.714 \pm 0.05$ \\
\hline 214 & $376.2 \pm 3.6$ & $3.446 \pm 0.07$ & $163.7 \pm 1.9$ & $2.829 \pm 0.12$ & $229.6 \pm 1.5$ & $1.745 \pm 0.05$ \\
\hline 247 & $371.6 \pm 6.3$ & $3.613 \pm 0.13$ & $167.0 \pm 3.3$ & $2.753 \pm 0.21$ & $232.7 \pm 2.1$ & $1.735 \pm 0.07$ \\
\hline 332 & $378.4 \pm 5.2$ & $3.794 \pm 0.11$ & $172.6 \pm 2.5$ & $2.859 \pm 0.17$ & $236.5 \pm 1.8$ & $1.906 \pm 0.08$ \\
\hline 369 & $384.1 \pm 7.7$ & $3.896 \pm 0.16$ & $173.7 \pm 3.2$ & $3.111 \pm 0.25$ & $236.4 \pm 2.3$ & $2.128 \pm 0.12$ \\
\hline 371 & $371.9 \pm 7.2$ & $4.094 \pm 0.18$ & $177.6 \pm 3.4$ & $2.766 \pm 0.24$ & $237.9 \pm 2.1$ & $2.013 \pm 0.10$ \\
\hline 398 & $359.4 \pm 11$ & $4.608 \pm 0.40$ & $184.8 \pm 5.9$ & $2.538 \pm 0.40$ & $241.4 \pm 3.2$ & $2.045 \pm 0.17$ \\
\hline 409 & $357.9 \pm 5.3$ & $4.771 \pm 0.19$ & $185.9 \pm 1.9$ & $2.593 \pm 0.14$ & $240.7 \pm 1.3$ & $2.176 \pm 0.08$ \\
\hline 422 & $357.5 \pm 15$ & $4.860 \pm 0.54$ & $183.7 \pm 4.8$ & $2.845 \pm 0.37$ & $239.6 \pm 3.2$ & $2.305 \pm 0.19$ \\
\hline 430 & $354.2 \pm 6.7$ & $5.026 \pm 0.28$ & $193.7 \pm 3.5$ & $2.249 \pm 0.23$ & $244.3 \pm 2.2$ & $2.126 \pm 0.13$ \\
\hline
\end{tabular}

The existence of a phenomenon of glass transition was found by direct methods both for protein solutions (Kuwai et al., 2006; Panagopoulou et al., 2012) and for hydrated protein powders (Noel et al., 1995; Frontzek et al., 2014; Sartor et al., 1994; Khodadadi et al., 2010; Morozov \& Gevorkian, 1985; Jansson \& Swenson, 2010). The results obtained show the same general feature: the glass-transition temperature of the mixture (or the solution) increases with decreasing water content. For example, calorimetric studies of lysozyme, myoglobine and albumin showed that, with the lowering of the hydration level, the glass transition of the mixture increases from $130 \mathrm{~K}$ to $240 \mathrm{~K}$ (Morozov \& Gevorkian, 1985); the glass transition process in hydrated hemoglobin extends from about $150 \mathrm{~K}$ up to temperature of denaturation (Sartor et al., 1994); the glass transition temperature of elastin increases from about $280 \mathrm{~K}$ (with water content $0.3 \mathrm{~g}$ water/g dry elastin) to about $470 \mathrm{~K}$ (with water content $0.01 \mathrm{~g}$ water / g dry elastin) (Kakivaya \& Hoeve, 1975) and the glass transition temperature of several hydrated wheat gluten proteins is in the range of about $280 \mathrm{~K}$ to $410 \mathrm{~K}$ (Noel et al., 1995).

The glass transition temperatures for ovalbumin solutions obtained in this work (Figure 2) are in the range from $138 \mathrm{~K}$ (for $\mathrm{c}=6.16 \mathrm{~kg} / \mathrm{m}^{3}$ ) to $188 \mathrm{~K}$ (for $\mathrm{c}=$ $430 \mathrm{~kg} / \mathrm{m}^{3}$ ). As can be seen, these values are in the range of the glass transition temperatures for the hydrated proteins reported in the literature. The rise of glass 
transition temperature with a decrease of hydration level of protein is usually explained by plasticizing effect of water (Doster, 2010; Frontzek et al., 2014). It is also noteworthy that the process of the glass transition of hydrated protein depends not only on the degree of hydration but also on the cooling rate. For this reason, the glass transition temperature for the particular system obtained by different authors may be quite different. For example, the glass transition temperature for myoglobin obtained from differential scanning calorimetry method lies in the range $190 \mathrm{~K}$ to $210 \mathrm{~K}$ (Jansson \& Swenson, 2010), and deduced from molecular dynamics simulation is equal to $220 \mathrm{~K}$ (Steinbach \& Brooks, 1993). Therefore, the comparison of the glass transition temperatures for a particular protein obtained by different methods is by all means desirable.

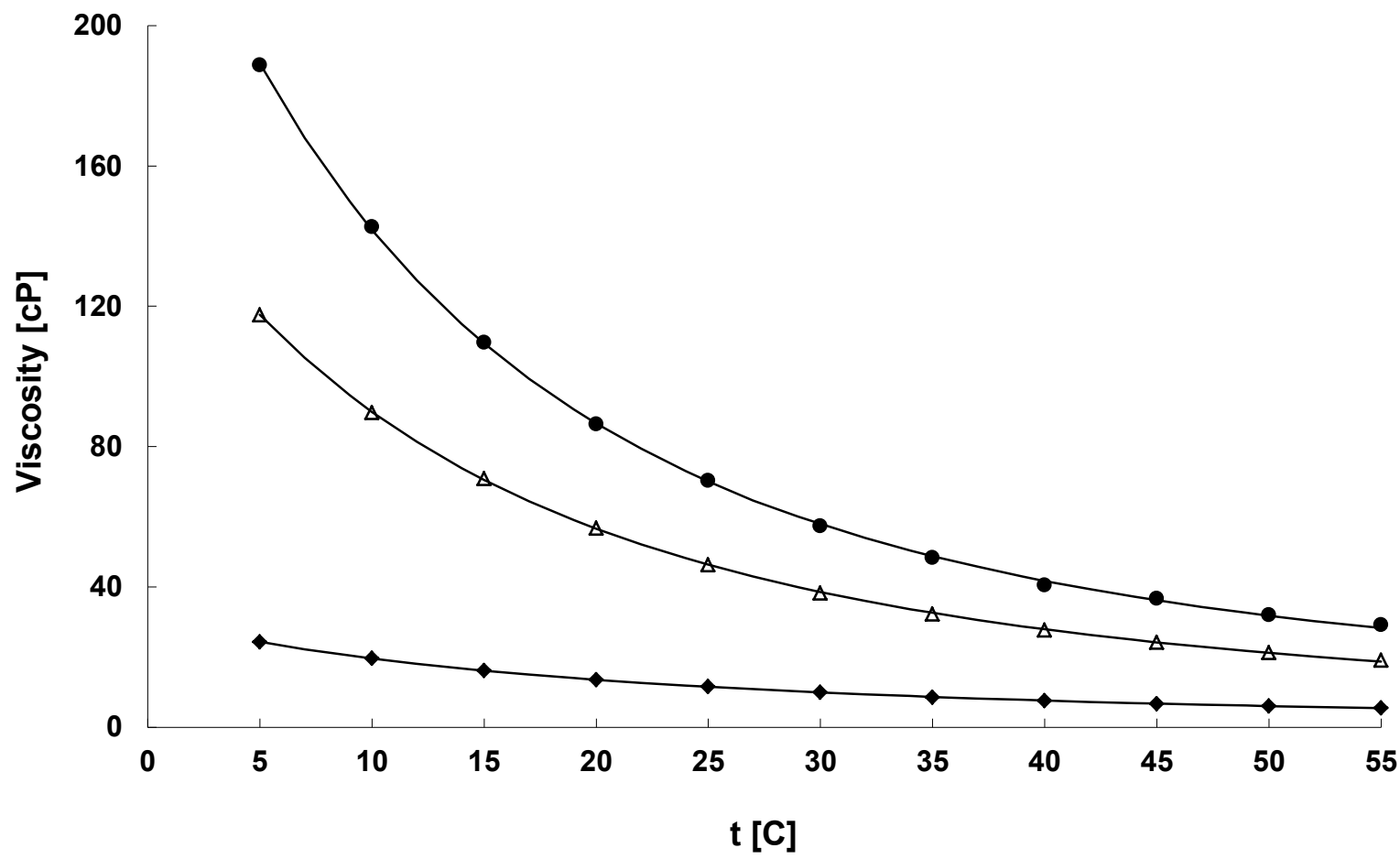

Fig. 1. Temperature dependence of the viscosity of ovalbumin aqueous solutions for concentrations: $\mathrm{c}=430 \mathrm{~kg} / \mathrm{m}^{3}(\bullet), \mathrm{c}=409 \mathrm{~kg} / \mathrm{m}^{3}(\Delta)$ and $\mathrm{c}=332 \mathrm{~kg} / \mathrm{m}^{3}(\diamond)$. The curves show the fit obtained by using: equation (1) with the parameters $\eta_{\infty}(\mathrm{c})=6.518 \mathrm{cP}, \Theta(\mathrm{c})=354.2 \mathrm{~K}$ and $\alpha(\mathrm{c})$ $=5.026$ for $\mathrm{c}=430 \mathrm{~kg} / \mathrm{m}^{3}$; equation (6) with the parameters $\mathrm{W}_{\mathrm{s}}(\mathrm{c})=0.6312 \mathrm{cP}, \mathrm{T}_{\mathrm{o}, \mathrm{s}}(\mathrm{c})=185.9 \mathrm{~K}$ and $\mathrm{F}_{\mathrm{s}}(\mathrm{c})=2.593$ for $\mathrm{c}=409 \mathrm{~kg} / \mathrm{m}^{3}$; equation (8) with the parameters $\mathrm{A}(\mathrm{c})=2.985 \times 10^{4} \mathrm{cP}, \mathrm{T}_{\mathrm{p}}(\mathrm{c})=236.5 \mathrm{~K}$ and $\mu(\mathrm{c})=1.906$ for $\mathrm{c}=332 \mathrm{~kg} / \mathrm{m}^{3}$.

The experimental observations indicate that the dry lyophilized proteins exhibit strongly suppressed dynamics and do not manifest a biological activity. Therefore, until recently, some authors have questioned the possibility of the glass transition in dry proteins. Now it has been demonstrated experimentally that this phenomenon actually occurs in dry proteins (Frontzek et al., 2014). The authors measured the mean-square atomic displacement $\left\langle\mathrm{x}^{2}\right\rangle$ in lyophilized bovine serum albumin powder by using the incoherent inelastic neutron scattering method. Anomalous temperature behavior of the mean-square atomic displacement and vibrational and relaxational dynamics, revealed in the vicinity of $250 \mathrm{~K}$, shows that the glass-like transition occurs in the dry proteins. As far as I know this is the only direct measurement of the glass transition temperature of dry protein. Typically, in this case,
Gordon-Taylor equation is used, or the results of measurements of the glass transition temperature are extrapolated to zero hydration. For example, the latter method gives - for dry elastin - glass transition temperature above $473 \mathrm{~K}$ (Bhandari \& Howes, 1999). In turn, the Gordon-Taylor equation applied to several hydrated wheat gluten proteins gave the following glass transition temperatures of the dry proteins: $397 \mathrm{~K}$ for $\gamma$ gliadin, $412 \mathrm{~K}$ for high-molecular-weight subunits of glutenin, $417 \mathrm{~K}$ for $\alpha$-gliadin and $418 \mathrm{~K}$ for $\omega$-gliadin (Noel et al., 1995). The use of the Gordon-Taylor equation to solutions of mammalian serum albumins, gave glass transition temperature for dry albumins within the range of $(215.4 \pm 7) \mathrm{K}$ for rabbit serum albumin to $(245.5 \pm 6.2) \mathrm{K}$ for human serum albumin (Monkos, 2015). As seen the glass transition temperature obtained in the present work for dry 
ovalbumin $(231.8 \mathrm{~K})$ lies in this range. It is also seen that the glass transition temperature of dry bovine serum albumin obtained by a mentioned above direct method $(250 \mathrm{~K})$ is consistent (within experimental error) with a glass transition temperature of dry human serum albumin deduced from indirect method. Similar glass transition temperature values were obtained for several other dry proteins such as: bovine $\beta$-lactoglobulin (227.3 $\pm 13) \mathrm{K}$, porcine immunoglobulin $\operatorname{IgG}(240.9 \pm 4.5) \mathrm{K}$, human immunoglobulin $\operatorname{IgG}(241.7 \pm 5.6) \mathrm{K}$ and hen egg-white lysozyme (260.6 \pm 5.6) K (Monkos, 2014). In general, however, as shown in the above examples, the glass transition temperatures of the dry proteins are significantly different from each other. The reason for this diversity may lie in differences of both conformation and rigidity/elasticity of a whole proteins molecules (Monkos, 2015).

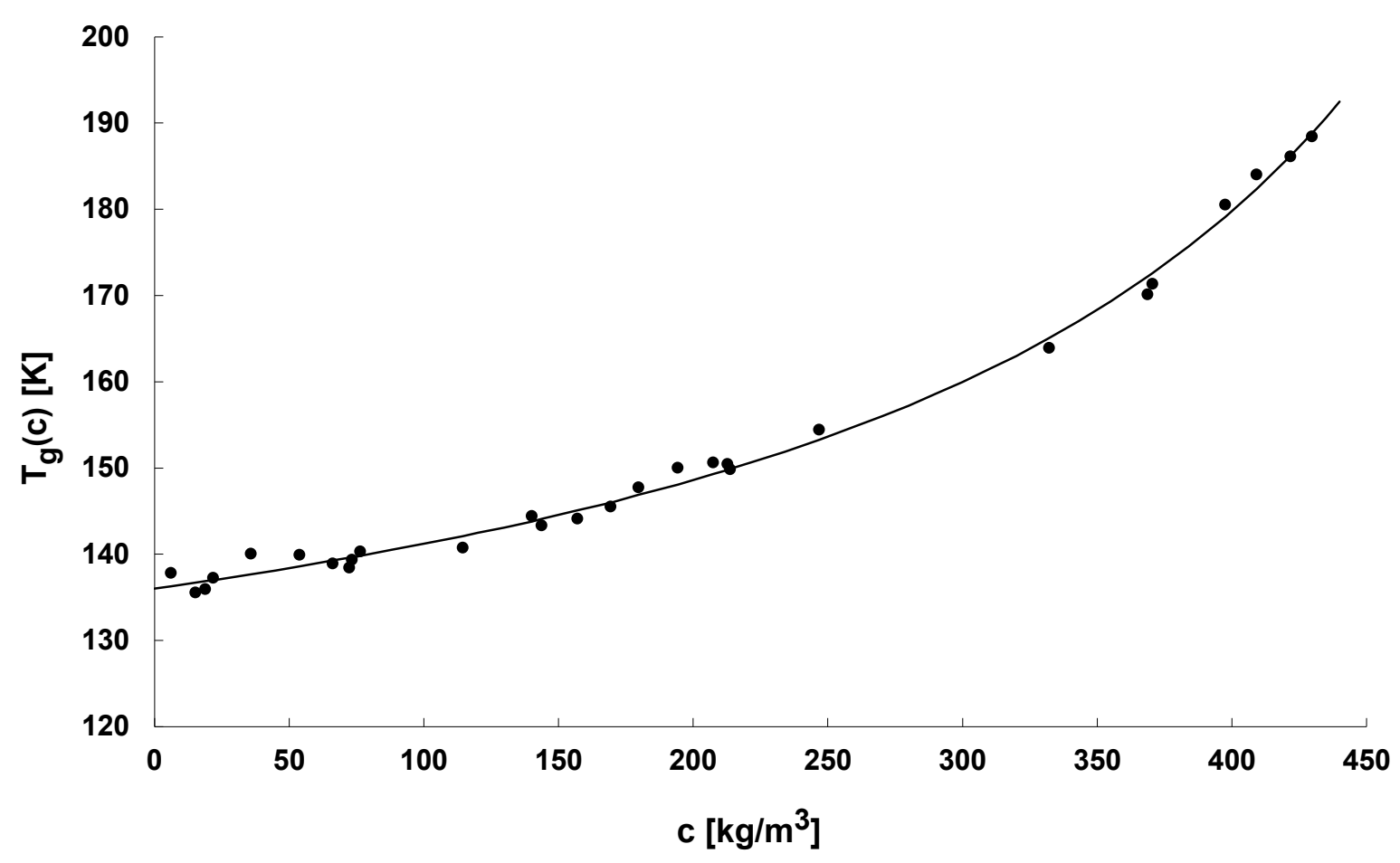

Fig. 2. Plot of the glass-transition temperature $\mathrm{T}_{\mathrm{g}}(\mathrm{c})$ of the ovalbumin aqueous solutions versus concentration; $(\bullet)$ experimental points. The curve shows the fit according to relation (2) with the parameters $\mathrm{T}_{\mathrm{g}, \mathrm{p}}=231.8 \mathrm{~K}, \mathrm{~T}_{\mathrm{g}, \mathrm{w}}=136 \mathrm{~K}, \mathrm{k}=2.165$ and $\xi=1.951 \times 10^{-3} \mathrm{~m}^{3} / \mathrm{kg}$.

The glass transition temperature of a protein is an important parameter because it determines its thermostability (Khatkar et al., 2013). The higher the glass transition temperature of the protein, the lesser protein is susceptible to unfolding and denaturation at lower temperatures.

\section{THE ACTIVATION ENERGY OF VISCOUS FLOW}

To understand the molecular dynamics of proteins in solution their hydrodynamic properties and, in particular, knowledge about the energetic characteristics of their viscous flow is important. The most important parameter that characterizes the flow of viscous liquids is the activation energy of viscous flow $\Delta \mathrm{E}$. The classical definition of this quantity was given within the frame of applications of the absolute rate theory to the process of flow (Vinogradov \& Malkin, 1980; Fox et al., 1956). According to this definition, $\Delta \mathrm{E}$ is a minimum energy required for a molecule to escape the influence of its neighbouring molecules or the energy for the jump of a molecule from one equilibrium position in the liquid to the next. Within a limited temperature range, the viscosity of a protein solution varies following a wellknown Arrhenius formula. In this case, viscosity $\eta$ (on a logarithmic scale) is proportional to the reciprocal of the absolute temperature, and $\Delta \mathrm{E}$ can be obtained from the slope of a straight line in the so-called Arrhenius plot, i.e. the plot of $\ln \eta$ versus $\mathrm{T}^{-1}$. However, it should be noted that the activation energy thus obtained is an average value from the temperature range in which the viscosity measurements were made. Viscosity data when taken in a wide range of temperatures show a non- 
Arrhenius behavior, i.e. the plot of $\ln \eta$ versus $\mathrm{T}^{-1}$ turns out to be non-linear. This means that the $\Delta \mathrm{E}$ depends on the temperature. The activation energy at any selected temperature is equal to the slope of the tangent to the curve on the Arrhenius plot. From a mathematical point of view it is a derivative. So for solutions, in which $\Delta \mathrm{E}$ depends on both temperature and concentration, the activation energy can be defined as follows:

$$
\Delta E(c, T)=R \frac{d \ln \eta(c, T)}{d T^{-1}}
$$

where $\mathrm{R}$ is a gas constant. In practice, if measurements of viscosity are made for a number of concentrations and at a wide range of temperatures, it is not possible to make the viscosity measurements - for each concentration - for too many temperatures. It is rather reasonable to use the functional dependence of viscosity on temperature, resulting from the specific model of viscous flow of the liquid and then - based on the above definition - obtain functional dependence of activation energy on temperature. In this paper, such functional relationship was obtained from the three models of a viscous liquid flow.

On the other hand, the activation energy of the aqueous protein solution at a given temperature depends on the activation energy of dissolved protein molecules $\Delta \mathrm{E}_{\mathrm{p}}(\mathrm{T})$ and water molecules $\Delta \mathrm{E}_{\mathrm{w}}(\mathrm{T})$ at the same temperature. As shown in earlier work (Monkos, 1996):

$$
\begin{aligned}
& \Delta E(c, T)= \\
& \frac{c}{\chi-\beta c}\left[\Delta E_{p}(T)-\Delta E_{w}(T)\right]+\Delta E_{w}(T)
\end{aligned}
$$

where $\chi=\rho_{\mathrm{w}} \mathrm{M}_{\mathrm{h}} / \mathrm{M}_{\mathrm{w}}$, and $\beta=\chi \xi$ - 1 . The quantities $\mathrm{M}_{\mathrm{h}}$ and $\mathrm{M}_{\mathrm{w}}$ denote the molecular masses of the dissolved protein and water, respectively. In physiological conditions proteins exist in water environment. Some water molecules fill the cavities inside proteins and some exist on the proteins surface forming a shell of water molecules. These two types of water molecules, forming a so-called "bound" water, migrate with protein molecules and make their own contribution to the hydrodynamic mass of the protein. Therefore, the molecular mass of hydrated protein should be considered as the sum of the molecular mass of unhydrated protein $\mathrm{M}_{\mathrm{p}}$ and the mass of "bound" water: $\mathrm{M}_{\mathrm{h}}=\mathrm{M}_{\mathrm{p}}(1+\delta)$. The quantity $\delta$ means the level of protein hydration and is defined as the amount of grams of water associated with the protein per gram of protein. It was experimentally found that $\delta$ does not depend on temperature (Ferrer et al., 2001) and concentration of a solution (Menon \& Allen, 1990). For ovalbumin $\mathbf{M}_{\mathrm{p}}=$ $45 \mathrm{kDa}$ (Stein et al., 1991) and $\delta=0.36$ (Young, 1963). It gives the molecular mass of hydrated ovalbumin $\mathrm{M}_{\mathrm{h}}=$ $61.2 \mathrm{kDa}$ and $\chi=3.4 \times 10^{6} \mathrm{~kg} / \mathrm{m}^{3}$. To calculate the activation energy of the ovalbumin $\Delta \mathrm{E}_{\mathrm{p}}(\mathrm{T})$ from equation (4) the activation energy of the solution $\Delta \mathrm{E}(\mathrm{c}, \mathrm{T})$ is required. We determine it from three models of the viscous liquid flow.

\section{Avramov's model}

Avramov's model assumes that the molecules in the flowing liquid perform jumps from the holes created by neighboring molecules to one of the adjoining holes (Avramov, 1998). According to the model viscosity of the liquid is inversely proportional to the average frequency of these jumps. At a fixed temperature, jumps frequency varies for different molecules and decreases exponentially with increasing the energy barrier that molecule must overcome during a jump. The assumption that the jumps frequency has a Poisson distribution allows to calculate the average jumps frequency. All these assumptions made it possible to obtain temperature dependence of the viscosity in the form shown in equation (1).

This equation gives the functional dependence of the viscosity on temperature and can be used for obtaining the functional dependence of the activation energy of viscous flow on temperature. After inserting the equation (1) into the definition (3), differentiation and simple transformations we obtain the following expression for the activation energy of the solution (Monkos, 2011a):

$$
\Delta E(c, T)=R T \alpha(c)\left[\frac{\Theta(c)}{T}\right]^{\alpha(c)}
$$

As can be seen $\Delta \mathrm{E}(\mathrm{c}, \mathrm{T})$ depends only on the two parameters of the Avramov's equation: $\Theta(c)$ and $\alpha(c)$. The numerical values of these parameters obtained for ovalbumin solutions, for all measured concentrations, are summarized in Table 1 . The values of the activation energy $\Delta E(c, T)$ calculated on the basis of the above equation for ovalbumin solutions at a temperature of $5^{\circ} \mathrm{C}$ are, in turn, presented in Figure 3. As shown the activation energy of the solution increases with increasing concentration of the solution. The function of the formula (4) can now fit into thus obtained experimental values.

At $\mathrm{c}=0$, the equation (1) describes the temperature dependence of water viscosity. Using the values of water viscosity from the standard physicochemical tables, the following numerical values of the parameters for water 
can be obtained: $\Theta_{\mathrm{w}}=395.7 \mathrm{~K}$ and $\alpha_{\mathrm{w}}=2.958$. From relation (1) can then calculate the activation energy of the water for any given temperature, and in particular: $\Delta \mathrm{E}_{\mathrm{w}}(\mathrm{T})=19.41 \mathrm{~kJ} / \mathrm{mol}$ at $5^{\circ} \mathrm{C}$ and $\Delta \mathrm{E}_{\mathrm{w}}(\mathrm{T})=14.04$ $\mathrm{kJ} / \mathrm{mol}$ at $55^{\circ} \mathrm{C}$. If the activation energy of water is known, then in the formula (4) the only unknown parameter is the activation energy of protein $\Delta \mathrm{E}_{\mathrm{p}}(\mathrm{T})$. It may be determined by least squares method. Thus calculated values of $\Delta \mathrm{E}_{\mathrm{p}}(\mathrm{T})$ for ovalbumin are presented in Table 2. As seen, the activation energy of viscous flow for ovalbumin strongly decreases with increasing temperature. The fitting curve shown in Figure (3) at a temperature of $5^{\circ} \mathrm{C}$, was obtained based on the relation (4) with the parameters set out in the above manner. As seen it gives a good fit to the experimental points. This is also the case for the other measured temperatures.

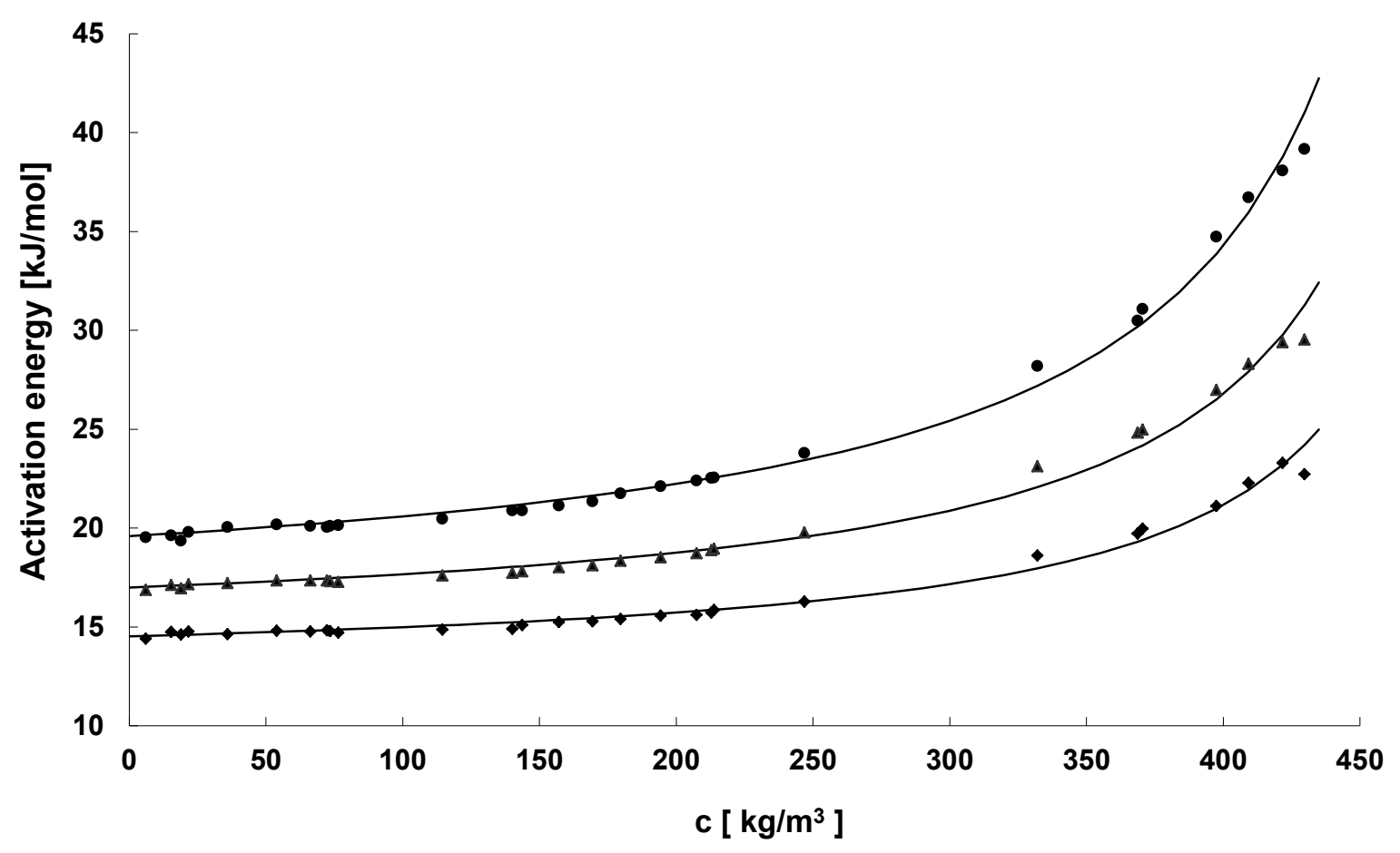

Fig. 3. Plot of the solution activation energy $\Delta \mathrm{E}(\mathrm{c}, \mathrm{T})$ versus concentration $\mathrm{c}$ at $\mathrm{t}=5^{\circ} \mathrm{C}(\bullet), \mathrm{t}=25^{\circ} \mathrm{C}(\boldsymbol{\Delta})$ and $\mathrm{t}=55^{\circ} \mathrm{C}(\bullet)$ for ovalbumin. Experimental points were obtained on the basis of equations (5), (7) and (9), respectively. The curves show the fit according to equation (4) with the parameters: $\alpha=3.4 \times 10^{6} \mathrm{~kg} / \mathrm{m}^{3}, \xi=1.951 \times 10^{-3} \mathrm{~m}^{3} / \mathrm{kg}$ and $\Delta \mathrm{E}_{\mathrm{p}}(\mathrm{T})=2.745 \times 10^{4} \mathrm{~kJ} / \mathrm{mol}, \Delta \mathrm{E}_{\mathrm{w}}(\mathrm{T})=19,41 \mathrm{~kJ} / \mathrm{mol}$ at t $=5^{\circ} \mathrm{C}$; $\Delta \mathrm{E}_{\mathrm{p}}(\mathrm{T})=1.829 \times 10^{4} \mathrm{~kJ} / \mathrm{mol}, \Delta \mathrm{E}_{\mathrm{w}}(\mathrm{T})=17 \mathrm{~kJ} / \mathrm{mol}$ at $\mathrm{t}=25^{\circ} \mathrm{C} ; \Delta \mathrm{E}_{\mathrm{p}}(\mathrm{T})=1.24 \times 10^{4} \mathrm{~kJ} / \mathrm{mol}, \Delta \mathrm{E}_{\mathrm{w}}(\mathrm{T})=14.15 \mathrm{~kJ} / \mathrm{mol}$ at $\mathrm{t}=55^{\circ} \mathrm{C}$.

Free-volume model

In the free volume model, is assumed that a fluid flows owing to jumps of molecules in the holes formed by the adjacent molecules due to density fluctuations (Vinogradov \& Malkin, 1980). In order to jumps could occur the holes must be sufficiently large. The "free volume" is defined as the volume unoccupied by the molecules and represents the volume available for their free movements. The temperature at which the free volume is equal to zero is called the ideal glass transition temperature $T_{0}$. The development of the above idea by Williams, Landel and Ferry leads to the viscosity-temperature formula which can be applied for temperatures from $T_{g}$ to $\left(T_{g}+100 \mathrm{~K}\right)$. This formula, on the assumption that - at temperatures higher than $T_{o}$ free volume increases linearly with the temperature, leads to the Vogel-Tammann-Fulcher's (VTF) equation
(Vinogradov \& Malkin, 1980). For solutions, and with modification proposed by Angell (Angell, 1988), it has the following form:

$$
\eta(c, T)=W_{s}(c) \exp \left[\frac{F_{s}(c) T_{o, s}(c)}{T-T_{o, s}(c)}\right]
$$

Parameters $\mathrm{W}_{\mathrm{s}}(\mathrm{c}), \mathrm{F}_{\mathrm{s}}(\mathrm{c})$ and $\mathrm{T}_{\mathrm{o}, \mathrm{s}}(\mathrm{c})$ depend only on concentration. This equation gives once again the functional dependence of viscosity on temperature. The parameters in the above equation were determined using non-linear regression procedure in the computational statistical program. Figure 1 shows the results of viscosity measurements for ovalbumin solution at $\mathrm{c}=$ 
$409 \mathrm{~kg} / \mathrm{m}^{3}$ over the whole range of measured temperatures and the curve presents the fit to the experimental points according to the above equation. As seen this function also gives a very good fit to the experimental points in the whole temperature range. The numerical values of the parameters $\mathrm{F}_{\mathrm{s}}(\mathrm{c})$ and $\mathrm{T}_{\mathrm{o}, \mathrm{s}}(\mathrm{c})$, which are important in the further part of this work, for all measured concentrations of ovalbumin, are gathered in Table 1.

Table 2. The activation energy of viscous flow $\Delta \mathrm{E}_{\mathrm{p}}(\mathrm{T})$ for ovalbumin molecules obtained from the studied models. Values of $\Delta \mathrm{E}_{\mathrm{p}}(\mathrm{T})$ are expressed as mean $\pm \mathrm{SE}$.

\begin{tabular}{cccc}
\hline $\mathrm{t}\left[{ }^{\mathrm{o}} \mathrm{C}\right]$ & $\begin{array}{c}\text { Avramov's model } \\
10^{-4} \times \Delta \mathrm{E}_{\mathrm{p}}(\mathrm{T})[\mathrm{kJ} / \mathrm{mol}]\end{array}$ & $\begin{array}{c}\text { Free volume model } \\
10^{-4} \times \Delta \mathrm{E}_{\mathrm{p}}(\mathrm{T})[\mathrm{kJ} / \mathrm{mol}]\end{array}$ & $\begin{array}{c}\text { Power law model } \\
10^{-4} \times \Delta \mathrm{E}_{\mathrm{p}}(\mathrm{T})[\mathrm{kJ} / \mathrm{mol}]\end{array}$ \\
\hline 5 & $2.745 \pm 0.052$ & $2.711 \pm 0.055$ & $2.814 \pm 0.061$ \\
10 & $2.478 \pm 0.052$ & $2.437 \pm 0.054$ & $2.451 \pm 0.056$ \\
15 & $2.236 \pm 0.052$ & $2.204 \pm 0.052$ & $2.177 \pm 0.052$ \\
20 & $2.016 \pm 0.051$ & $2.003 \pm 0.051$ & $1.964 \pm 0.050$ \\
25 & $1.817 \pm 0.051$ & $1.829 \pm 0.050$ & $1.795 \pm 0.047$ \\
30 & $1.635 \pm 0.051$ & $1.677 \pm 0.049$ & $1.659 \pm 0.046$ \\
35 & $1.469 \pm 0.050$ & $1.544 \pm 0.048$ & $1.543 \pm 0.044$ \\
40 & $1.319 \pm 0.050$ & $1.427 \pm 0.047$ & $1.449 \pm 0.042$ \\
45 & $1.181 \pm 0.049$ & $1.323 \pm 0.046$ & $1.368 \pm 0.041$ \\
50 & $1.055 \pm 0.049$ & $1.231 \pm 0.045$ & $1.299 \pm 0.040$ \\
55 & $0.940 \pm 0.048$ & $1.148 \pm 0.044$ & $1.240 \pm 0.039$ \\
\hline
\end{tabular}

As in the Avramov's model function from relation (6) can insert to the definition (3) and obtain the functional dependence of the activation energy of the solution (Monkos, 2011a):

$$
\Delta E(c, T)=\frac{R F_{s}(c) T_{o, s}(c) T^{2}}{\left[T-T_{o, s}(c)\right]^{2}}
$$

Similarly to the previous model activation energy of the solution depends only on the two parameters $F_{s}(c)$ and $\mathrm{T}_{\mathrm{o}, \mathrm{s}}(\mathrm{c})$. Experimental values of the activation energy for ovalbumin solutions at temperature $25^{\circ} \mathrm{C}$, obtained from above formula are shown in Figure 3.

At $\mathrm{c}=0$, the above formula describes the activation energy of water. One can easily show that for water: $F_{w}$ $=3.57$ and $\mathrm{T}_{\mathrm{o}, \mathrm{w}}=147 \mathrm{~K}$. Formula (7) gives then the values of the activation energy of the water only slightly different from those obtained from Eq. (5): $\Delta \mathrm{E}_{\mathrm{w}}(\mathrm{T})=$ $19.52 \mathrm{~kJ} / \mathrm{mol}$ at $5^{\circ} \mathrm{C}$ to $\Delta \mathrm{E}_{\mathrm{w}}(\mathrm{T})=14.25 \mathrm{~kJ} / \mathrm{mol}$ at $55^{\circ} \mathrm{C}$. Having the activation energy of water one can function from relation (4) fit to the experimental points indirectly obtained from the Eq. (7). The activation energy of the protein $\Delta \mathrm{E}_{\mathrm{p}}(\mathrm{T})$ is again the only fitting parameter. The values of $\Delta \mathrm{E}_{\mathrm{p}}(\mathrm{T})$ obtained for ovalbumin by using the least squares method are shown in Table 2. An exemplary fitting curve, with thus obtained values of $\Delta \mathrm{E}_{\mathrm{p}}(\mathrm{T})$, for temperature of $25^{\circ} \mathrm{C}$, is shown in Figure 3. We get equally good fit as for the Avramov's model.

\section{Power-law model}

Taborek and his colleagues performed highly precise measurements of the viscosity of the pure inorganic liquids such as water, methanol, benzene and many others, as well as for solutions such as, for example aqueous solutions of lithium chloride (Taborek et al., 1986). Results of these measurements showed that above a certain characteristic temperature $T_{p}$, which lies in the supercooled metastable liquid regime, the viscosity - over a broad temperature range - can be described by a power-type relation. The success of the power-law description for a wide variety of liquids suggests that $T_{p}$ has a real physical significance, but so far there is no for it clear theoretical explanation. It is known, however, that $\mathrm{T}_{\mathrm{p}}$ does not coincide with the glass transition temperature. For solutions, this proposed relationship between viscosity and temperature is as follows:

$$
\eta(c, T)=A(c)\left[T-T_{p}(c)\right]^{-\mu(c)}
$$

The parameters $A(c), T_{p}(c)$ and $\mu(c)$ depend only on concentration. As with the two previous models, these parameters can be determined using non-linear regression procedure in the computational statistical program. Figure 1 presents the results of viscosity measurements for ovalbumin solution at $\mathrm{c}=332 \mathrm{~kg} / \mathrm{m}^{3}$ over the whole range of measured temperatures. The curve shows the fit to these experimental points according to above relation. Is seen that this model gives equally good fit to the experimental points as the two previous models. The authors of this model maintain that for the examined by them liquids relation (8) better describes the temperature dependence of the viscosity than the Arrhenius or VTF formula. For the original 
Arrhenius formula it is obvious because this is twoparameter equation and describes the dependence of viscosity on temperature only in a narrow temperature range.

The insertion of the function from formula (8) to the definition (3) gives the following equation for the activation energy of a solution (Monkos, 2011a):

$$
\Delta E(c, T)=R \mu(c) \frac{T^{2}}{T-T_{p}(c)}
$$

Hence, in this model, the activation energy of a solution also depends on only two parameters: $\mathrm{T}_{\mathrm{p}}(\mathrm{c})$ and $\mu(\mathrm{c})$. The numerical values of these parameters for ovalbumin solutions, for all measured concentrations, are summarized in Table 1. As has been shown in original paper (Taborek et al., 1986), the exponent $\mu$ in formula (8) is not universal, but lies in the range between 1.5 and 2.3. As seen in Table (1) all values of this parameter obtained for ovalbumin solutions examined here are also located in this narrow range. In Figure (3) the values of the activation energy for measured ovalbumin solutions, obtained from the equation (9) at temperature $55^{\circ} \mathrm{C}$, are shown.

At $\mathrm{c}=0$, the formula (8) describes the temperature dependence of water viscosity with the parameters $\mathrm{A}_{\mathrm{w}}=$ $711 \mathrm{cP}, \mathrm{T}_{\mathrm{p}, \mathrm{w}}=228.5 \mathrm{~K}$ and $\mu_{\mathrm{w}}=1.574$. These parameters allow to calculate the activation energy of water from relation (9): $\Delta \mathrm{E}_{\mathrm{w}}(\mathrm{T})=20.4 \mathrm{~kJ} / \mathrm{mol}$ at $5^{\circ} \mathrm{C}$ to $\Delta \mathrm{E}_{\mathrm{w}}(\mathrm{T})=14.15 \mathrm{~kJ} / \mathrm{mol}$ at $55^{\circ} \mathrm{C}$. Similarly to the previous two models, the function from formula (4) can now fit to the experimental points treating $\Delta \mathrm{E}_{\mathrm{p}}(\mathrm{T})$ as fitting parameter. The values of $\Delta \mathrm{E}_{\mathrm{p}}(\mathrm{T})$ calculated for ovalbumin by using the least squares method are summarized in Table 2. An exemplary fitting curve, for temperature of $55^{\circ} \mathrm{C}$, is also shown in Figure 3 and as seen we get equally good fit as for the two previous models.

Comparison of the results of $\Delta E_{p}(T)$ for ovalbumin obtained on the basis of different models

It is well known that the value of activation energy of viscous flow depends on the molecular mass of polymer (Vinogradov \& Malkin, 1980). This has been shown directly - among others - for globular and non-globular proteins with significantly different molecular mass (Monkos, 2007b). The study of solutions viscosity of human serum albumin at neutral $\mathrm{pH}$ and at the isoelectric point $(\mathrm{pI})$ revealed that the activation energy reaches a maximum value at pI (Monkos, 2013). Moreover, determination of the activation energy for the bovine serum albumin and human serum albumin at isoelectric point shows that $\Delta \mathrm{E}_{\mathrm{p}}$ depends on the dipole moment of the protein; the larger the dipole moment, the greater the value of activation energy (Monkos, 2013).
In turn, the study of various mammalian albumins which have similar or identical molecular mass - in solutions outside an isoelectric point showed that the activation energy depends also on their hydrodynamic radius (Monkos,2011b).

As seen in Table 2, each model discussed here predicts that the activation energy of ovalbumin molecules decreases with increasing temperature. $\Delta \mathrm{E}_{\mathrm{p}}(\mathrm{T})$ values obtained from free-volume model and power-law model are - within the error limits - nearly the same in the whole temperature range. $\Delta \mathrm{E}_{\mathrm{p}}(\mathrm{T})$ values obtained from Avramov's model are consistent with them up to a temperature of $35^{\circ} \mathrm{C}$, and for higher temperatures are slightly different. The activation energy of ovalbumin molecules at $5^{\circ} \mathrm{C}$ is higher than at $55^{\circ} \mathrm{C}: 2.92$ times for Avramov's model, 2.36 times for free-volume model and 2.27 times for power-law model. There is now the question, which factors affect not only the activation energy itself, but on its change with temperature.

It is known from the principle of equipartition of energy that the average energy of translational heat motion of molecules $\langle\mathrm{E}\rangle$ is independent of molecular mass and is equal to: $\langle\mathrm{E}\rangle=1.5 \mathrm{kT}$ ( $\mathrm{k}$ is Boltzmann constant). In the temperature range which was used for viscosity measurements on solutions of ovalbumin $\langle\mathrm{E}\rangle$ increases from $5.76 \times 10^{-21} \mathrm{~J}$ at $5^{\circ} \mathrm{C}$ to $6.796 \times 10^{-21} \mathrm{~J}$ at $55^{\circ} \mathrm{C}$. Thus, $\langle\mathrm{E}\rangle$ at $55^{\circ} \mathrm{C}$ is only 1.18 times higher than at $5^{\circ} \mathrm{C}$. This means that the increase in the energy of translational heat motion of molecules only partially explains the decrease in activation energy of ovalbumin molecules with increasing temperature.

Another factor that may influence changes in the activation energy with temperature are intermolecular interactions (de Paula \& Rodrigues, 1995). As mentioned above, the $\mathrm{pH}$ value of the ovalbumin solutions studied in the present work was equal to 6.4, i.e. was outside of the isoelectric point for ovalbumin which is in the range $(4.59-4.71)$ (Young, 1963). This means that in such solutions the ovalbumin molecules are charged as a whole. Because of covalent and noncovalent bonds between atoms in the ovalbumin molecule, spatial charge distribution in it is asymmetric. This asymmetry can be described by the dipole moment, quadrupole moment and higher moments of protein (Laberge, 1998). Like for many other proteins dipole moment of ovalbumin is well known and is $250 \mathrm{D}$ (Tanford, 1961). While higher moments are less explored. Because of complexity of the electrostatic properties of proteins, the protein-protein interactions are also complex. At the first approximation, the average force between proteins created by electrostatic interactions can be considered as sum of: (i) repulsion force caused by charge-charge interaction and (ii) attractive force caused by charge-dipole moment interaction, charge-induced dipole interaction, dipoledipole interaction, dipole-induced dipole interaction and 
dispersion interaction (Vilker et al., 1981). If the $\mathrm{pH}$ of a solution is outside the isoelectric point, the force caused by Coulomb repulsion between two molecules of ovalbumin partially balances the attractive forces caused by the remaining interactions. In consequence the resultant force of the electrostatic interactions between the ovalbumin molecules is low. This suggests that electrostatic protein-protein interactions should not have a significant effect on so essential changes in the activation energy of ovalbumin molecules with temperature.

A similar conclusion can also be drawn from the analysis of temperature variations in the Huggins coefficient $\mathrm{k}_{1}$ for ovalbumin. The Huggins coefficient is the quantitative measure of the protein-protein interactions (Dreval et al., 1973). In earlier work has shown that - for ovalbumin $-\mathrm{k}_{1}$ increases from the value 0.9792 (at $5^{\circ} \mathrm{C}$ ) to the value 1.0276 (at $55^{\circ} \mathrm{C}$ ) (Monkos, 2000). Thus at $55^{\circ} \mathrm{C}$ the Huggins coefficient is only 1.05 times higher than in the temperature of $5^{\circ} \mathrm{C}$. If the protein-protein interactions in solution are strong, the Huggins coefficient rapidly increases with increasing temperature (Desbrieres et al., 1996). This is not the case of ovalbumin. A small variations in the $\mathrm{k}_{1}$ with temperature indicate limited influence of protein-protein interactions on temperature changes in the activation energy of ovalbumin.

The intrinsic viscosity [ $\eta]$, in turn, which is a measure of the contribution of a protein to the viscosity of the solution depends on protein-solvent interactions (Pamies et al., 2008). The obtained earlier values of the intrinsic viscosity for ovalbumin decrease with increasing temperature from $4.07 \times 10^{-3} \mathrm{~m}^{3} / \mathrm{kg}$ at $5^{\circ} \mathrm{C}$ to $3.697 \times 10^{-3}$ $\mathrm{m}^{3} / \mathrm{kg}$ at $55^{\circ} \mathrm{C}$ (Monkos, 2000). Thus, the value [ $\left.\eta\right]$ at $5^{\circ} \mathrm{C}$ is 1.1 times greater than at $55^{\circ} \mathrm{C}$. This means that the protein-solvent interactions also have only a limited influence on the temperature dependence of the activation energy of ovalbumin.

Changes in activation energy with temperature can also be caused by a change in flexibility of protein in solution (de Paula \& Rodrigues, 1995). It is understood that the more flexible molecule is, the greater the probability of matching to the hole created by the adjacent molecules. Information on the flexibility/rigidity of the protein in solution can be indirectly obtained from analysis of the plot of the specific viscosity $\eta_{\mathrm{sp}}$ on the product of intrinsic viscosity $[\eta]$ and concentration. The dependence of $\eta_{\text {sp }}$ on $[\eta] c$ in a log-log plot for ovalbumin shows an existence of the transition from dilute to semi-dilute solution at a concentration $\mathrm{c}^{*}$, and from semi-dilute to concentrated solution at a concentration $c^{* *}$ (Monkos, 2000). Such master curve for ovalbumin has the same form over the whole range of measured temperatures. In the concentrated region $\left.([\eta] c\rangle[\eta] c^{* *}\right)$ the plot of $\log \eta_{\mathrm{sp}}-$ $\log [\eta] \mathrm{c}$ is linear. It has been experimentally demonstrated that the slope of the line in the $\log \eta_{\mathrm{sp}}$ $\log [\eta] \mathrm{c}$ plot in this region is a measure of protein flexibility/rigidity in a solution (Monkos, 2000 and references therein). For ovalbumin the slope in the concentrated region decreases from 8.41 at $5^{\circ} \mathrm{C}$ up to 7.06 at $55^{\circ} \mathrm{C}$. Thus, the slope at $5^{\circ} \mathrm{C}$ is 1.19 times greater than at $55^{\circ} \mathrm{C}$. For rigid molecules, the slope in this region should be approximately equal to 8 (Baird \& Ballman, 1979) and the smaller the slope the less rigid (or more flexible) molecule is. Thus, the ovalbumin molecules can be regarded as rigid. However, their rigidity decreases (or elasticity increases) with increasing temperature. As mentioned above, it is understood that increase in the flexibility of the molecules results in a reduction in the activation energy. However, setting quantitative relationship between these quantities is not easy.

Analysis of the activation energy for proteins having the same molecular mass shows that the hydrodynamic radius of the protein affects not only the value of the activation energy at fixed temperature but also on the rate of its reduction with increasing temperature (Monkos, 2011b). From the above analysis results that there are several factors that influence the rate of decrease in protein activation energy with temperature, but it is difficult to accurately estimate their quantitative contribution to this process. It should rather think that for each protein, this problem should be considered in the details separately.

\section{CONCLUSIONS}

Functional dependences of the viscosity on temperature resulting from Avramov's model, free-volume model and power law model provide equally good fit to the experimental values of viscosity for ovalbumin aqueous solutions at temperatures from $5^{\circ} \mathrm{C}$ to $55^{\circ} \mathrm{C}$ and in a wide range of concentrations. The glass transition temperature for ovalbumin solutions increases nonlinearly with increasing concentration of ovalbumin from $138 \mathrm{~K}$ (for $\mathrm{c}=6.16 \mathrm{~kg} / \mathrm{m}^{3}$ ) to $188 \mathrm{~K}$ (for $\mathrm{c}=430$ $\left.\mathrm{kg} / \mathrm{m}^{3}\right)$. In turn, the glass transition temperature of dry ovalbumin - deduced from the modified Gordon-Taylor equation - is equal to $(231.8 \pm 6.1) \mathrm{K}$. From the functional dependence of viscosity on temperature - for each model - the functional dependence of solution activation energy on temperature has been obtained. Then, the activation energy of ovalbumin molecules $\Delta \mathrm{E}_{\mathrm{p}}(\mathrm{T})$ has be calculated. Each model predicts that $\Delta \mathrm{E}_{\mathrm{p}}(\mathrm{T})$ for ovalbumin decreases with increasing temperature. The numerical values of $\Delta \mathrm{E}_{\mathrm{p}}(\mathrm{T})$ obtained from free-volume model and power-law model are within the error limits - nearly the same in the whole temperature range. Only the values of $\Delta \mathrm{E}_{\mathrm{p}}(\mathrm{T})$ obtained from the Avramov's model for temperatures above $35^{\circ} \mathrm{C}$ 
differ somewhat from those obtained from the previous two models. Nevertheless each model predicts that the activation energy of ovalbumin molecules at $5^{\circ} \mathrm{C}$ is more than two times higher than at $55^{\circ} \mathrm{C}$. Several factors influence the rate of decrease in activation energy of ovalbumin molecules with increasing temperature, but it is difficult to determine their exact contribution to this process.

\section{ACKNOWLEDGMENTS}

This work was supported by the project of MUS: KNW$1-047 / \mathrm{N} / 5 / 0$.

\section{REFERENCES}

Abeyrathne E.D.N.S., Lee H. Y., Ahn D. U. (2014). Sequential separation of lysozyme, ovomucin, ovotransferrin, and ovalbumin from egg white. Poultry Science 93, 1001-1009.

Ahmad F., Salahuddin A. (1976). Reversible unfolding of the major fraction of ovalbumin by guanidine hydrochloride. Biochemistry 15, 5168-5175.

Angell C.A. (1988). Perspective on the glass transition. $J$. Phys. Chem. Solids 8, 863-871.

Avramov I. (1998). Viscosity of glass forming melts. J. NonCryst.Solids 238, 6-10.

Baird D.G., Bellman R.L. (1979). Comparison of the rheological properties of concentrated solutions of a rodlike and a flexible chain polyamide. J. Rheol. 23, 505-524.

Bhandari B.R., Howes T. (1999). Implication of glass transition for the drying and stability of dried foods. J. Food Eng. 40, 71-79.

De Paula R.C.M., Rodrigues J.F. (1995). Composition and rheological properties of cashew tree gum, the exudates polysaccharide from Anticardium occidental L. Carbohydras. Polyp. 26, 177-181.

Desbrieres J., Martinez C., Rinaudo M. (1996). Hydrophobic derivatives of chitosan: characterization and rheological behavior. Int. J. Biol. Macromol. 19, 21-28.

Doster W. (2010). The protein-solvent transition. Biochim. Biophys. Acta 1804, 3-14.

Dreval V.E., Botvinnik G. O., Malkin A. Ya. (1973). Approach to generalization of concentration dependence of zero-shear viscosity in polymer solutions. J. Polym. Sci. 11, 1055-1076.

Ferrer M.L., Duchowich R., Carrasco B., Garcia de la Torre J. (2001). The conformation of serum albumin in solution: a combined phosphorescence depolarization- hydrodynamic modeling study. Biophys. J. 80, 2422-2430.

Fox T. G., Gratch S., Loshaek S. (1956). Viscositytemperature relationships for polymers. [In:] Eirich F.R. (ed.), Rheology. Theory and applications, vol. 1, Academic Press, New York, pp. 447-457.

Frauenfelder H., Sligar S.G., Wolynes P.G. (1991). The energy landscape and motions of proteins. Science 254, 1598-1603.
Frontzek A.V., Strokov S.V., Embs J.P., Lushnikov S.G. (2014). Does a dry protein undergo a glass transition? J. Phys. Chem. B 118, 2796-2802.

Gordon M., Taylor J.S. (1952). Ideal copolymers and the second-order transition of synthetic rubbers. J. Appl. Chem. 2, 493-499.

Hallbruker A., Mayer E., Johari G.P. (1989). The heat capacity and glass transition of hyper quenched glassy water. Phil. Mag. 60B, 179-187.

Ikeda S., Nishinari K. (2001). Solid-like mechanical behaviors of ovalbumin aqueous solutions. Int. J. Biol. Macromol. 28, 315-320.

Jansson H., Swenson J. (2010). The protein glass transition as measured by dielectric spectroscopy and differential scanning calorimetry. Biochim. Biophys. Acta 1804, 20-26.

Johari G.P., Hallbruker A., Mayer E. (1987). The glass transition of hyper quenched water. Nature 330, 552-553.

Kakivaya S.R., Hoeve C.A. (1975). The glass point of elastin. Proc. Nat. Acad. Sci. USA 72, 3505-3507.

Kang D., Ryu S.R., Park Y., Czarnik-Matusewicz B., Jung Y.M. (2014). PH-induced changes of ovalbumin studied by 2D correlation IR spectroscopy. J. Mol. Struct. 1069, 299304.

Katkov I.I., Levine F. (2004). Prediction of the glass transition temperature of water solutions: comparison of different models. Cryobiology 49, 62-82.

Khatkar B.S., Barak S., Mudgil D. (2013). Effects of gliadin addition on the rheological, microscopic and thermal characteristics of wheat gluten. Int. J. Biol. Macromol. 53, 38-41.

Khodadadi S, Malkovskiy A., Sokolov A.P. (2010). A broad glass transition in hydrated proteins. Biochim Biophys. Acta 1804, 15-19.

Khodarahmi R., Soori H., Karimi S. A. (2009), Chaperon-like activity of heme group against amyloid- like fibril formation by hen egg ovalbumin: Possible mechanism of action. Int. J. Biol. Macromol. 44, 98-106.

Kuwai K., Suzuki T., Oguni M. (2006). Lowtemperature glass transitions of quenched and annealed bosine serum albumin aqueous solutions. Biophys. J. 90, 17.

Laberge M. (1998). Intrinsic protein electric fields: basic noncovalent interactions and relationship to protein-induced stark effects. Biochim. Biophys. Acta 1386, 305-330.

Lefebvre J. (1982). Viscosity of concentrated protein solutions. Rheol. Acta 21, 620-625.

Lin Y.C., Chang Z.C., Lin C.B., Shen C.C., Su Y.L. (2012). Effect of curing temperature on properties and solvent welding strength of ovalbumin. J. Appl. Polym Sci. 124, 2144-2153.

McCarty B.J., Worrall D.M. (1997). Analysis of serpin inhibitory function by mutagenesis of ovalbumin and generation of chimeric ovalbumin/PAI-1 fusion proteins. J. Mol. Biol. 267, 561-569.

Menon R. S., Allen P.S. (1990). Solvent proton relaxation of aqueous solutions of the serum proteins $\alpha 2$-macroglobulin, fibrinogen, and albumin. Biophys. J. 57, 389-396.

Monkos K. (1996). Viscosity of bovine serum albumin aqueous solutions as a function of temperature and concentration. Int. J. Biol. Macromol. 18, 61-68. 
Monkos K. (2000). Viscosity analysis of the temperature dependence of the solution conformation of ovalbumin. Biophys. Chem. 85, 7-16.

Monkos K. (2007a). Temperature dependence of the activation energy of viscous flow for ovalbumin in aqueous solutions. Curr. Top. Biophys. 30, 29-33.

Monkos K. (2007b). Studies of protein solution conformations using viscometric measurements. [In:] Uversky V. \& Permyakov E. (eds.), Methods in protein structure and stability analysis, Nova Science Publishers, New York, pp. 355-387.

Monkos K. (2011a). A comparison of the activation energy of viscous flow for hen egg-white lysozyme obtained on the basis of different models of viscosity for glass-forming liquids. Curr. Top. Biophys. 34, 1-9.

Monkos K. (2011b). Temperature behavior of viscosity flow with proteins. Gen. Physiol. Biophys. 30, 121-129.

Monkos K. (2013). A viscometric approach of $\mathrm{pH}$ effect on hydrodynamic properties of human serum albumin in the normal form. Gen. Physiol. Biophys. 32, 67-78.

Monkos K. (2014). On the possibility of indirect determination of the glass transition temperature of proteins from viscosity measurements and Avramov's model. Curr. Top. Biophys. 37, 63-70.

Monkos K. (2015). Determination of the glass-transition temperature of proteins from a viscometric approach. Int. J. Biol. Macromol. 74, 1-4.

Morozov V. N., Gevorkian S. G. (1985). Lowtemperature glass transition in proteins. Biopolymers 24 , $1785-1799$

Nisbet A. D., Saundry R. H., Moir A. J. G., Fothergill L.A., Fothergill J.E. (1981). The complete amino-acid Sequence of hen ovalbumin. Eur. J. Biochem. 115, 335-345.

Noel T R., Parker R., Ring S.G. (1995). The glass-transition behavior of wheat gluten proteins. Int. J. Biol. Macromol. 17, 81-85.

Pamies R., Hernández J.G., del Carmel López Martinez M., Garcia de la Torre J. (2008). Determination of intrinsic viscosities of macromolecules and nanoparticles. Comparison of single-point and dilution procedures. Colloid. Polym. Sci. 286, 1223-1231.

Panagopoulou A., Kyritsis A., Shinyashiki N., Pissis P. (2012). Protein and water dynamics in bovine serum albumin water mixture over wide ranges of composition. $J$. Phys. Chem. B 116, 4593-4602.

Renault A., Pezennec S., Gauthier F., Vie W., Desbat B. (2002). Surface rheological properties of native and S- ovalbumin are correlated with the development of an intermolecular beta-sheet network at the air-water interface. Langmuir 18, 6887-6895.

Sartor G., Mayer E., Johari G.P. (1994). Calorimetric studies of the kinetic unfreezing of molecular motions in hydrated lysozyme, hemoglobin, and myoglobin. Biophys. J. 66, 249258.

Stein P.E., Leslie A. G. W., Finch J. T., Carrell R. W. (1991). Crystal structure of uncleaved ovalbumin at $1.95 \AA$ resolutions. J. Mol. Biol. 221, 941-959.

Steinbach P.J., Brooks B.R. (1993). Protein hydration elucidated by molecular dynamics simulation. Proc. Natl. Acad. Sci. USA 90, 9135-9139.

Taborek P., Kleiman R.N., Bishop D.J. (1986). Power-law behavior in the viscosity of super cooled liquids. Phys. Rev. B 34, 1835-1840.

Tanford C. (1961). Physical chemistry of macromolecules. Wiley, New York,

Tani F., Shirai N., Nakanishi Y., Yasumoto K., Kitabatake N. (2004). Role of the carbohydrate chain and two phosphate moieties in the heat-induced aggregation of hen ovalbumin. Biosci. Biotechnol.Biochem. 12, 24662476.

Teeter M.M., Yamano A., Stec B., Mohanty U. (2001). On the nature of a glassy state of matter in a hydrated protein: Relation to protein function. Proc. Natl. Acad. Sci. USA 98, 11242-11247.

Vilker V.L., Colton C.K., Smith K.A. (1981). The osmotic pressure of concentrated protein solutions: effect of concentration and $\mathrm{pH}$ in saline solutions of bovine serum albumin. J. Colloid. Interface Sci. 79, 548566.

Vinogradov G. V., Malkin A.Y. (1980). Rheology of polymers. Mir, Moscow.

Yang Y., Barendregt A., Kamerling J.P., Heck A.J.R. (2013). Analyzing protein micro-heterogeneity in chicken ovalbumin by high-resolution native mass spectrometry exposes qualitatively and seki-quantitatively 59 proteoforms. Anal. Chem. 85, 12037-12045.

Young E. G. (1963). Occurrence, classification, preparation and analysis of proteins. [In:] Florkin M., Stolz E.H. (eds.), Comprehensive Biochemistry, Amsterdam, pp. 22.

Zimmerman S.B., Minton A.P. (1993). Macromolecular crowding: biochemical, biophysical, and physiological consequences. Annu. Rev. Biophys. Biomol. Struct. 22, $27-$ 65 . 